\section{Bagasse for the Manufacture of Paper and Board}

THe many attempts to utilize bagasse for the manufacture of paper have met with varying degrees of success, partly for economic reasons and partly because the nature of bagasse often renders it suitable only for relatively low-grade products. M. P. Bhargava and A. N. Nayer, of the Dehra Dun Forest Research Institute, have, however, recently approached the problem from the other extreme, namely, that of the manufacture of boards, and in particular of insulation and pressed boards, a large potential demand for which exists in India (Imp. Council of Agric. Res., Misc. Bull., No. 44 ; 1941). The various processes available for the purpose were studied, but defibration in an Asplund-type machine was favoured on the grounds of the low installation and operating costs and of the quality of the product. The cost of afterwards rendering the boards resistant to moisture, fire and insects appears, however, to be disproportionately high. The samples accompanying the bulletin and the test data published in it suggest that, technically, the process is a promising one. The sample of bagasse wrapping-paper also sent is, however, less impressive; no test data are given, but obviously the fibre length is short, which means low tearing and folding strengths.

\section{A New X-Ray Photographic Paper}

MessRs. Ilford, LTD., have recently placed on the market, under the name 'Kryptoscreen', a new X-ray paper incorporating its own intensifying screen. Underneath the sensitive emulsion is a layer of extremely fine white pigment which fluoresces under the influence of X-rays. The blue-violet light emitted shortens exposure times and much improves the gradation of radiographs made on the paper. The search for a cheap fuorescent material which neither lowers the sensitivity of the photographic emulsion nor impairs definition has been carried on for many years by the Ilford Research Laboratories. The resulting product provides an economical substitute for film in the radiography of fractures of the extremities and in certain types of industrial radiography. The same fluorescing material has been used to make a 'Brytex Intensifying Leaf' of exceedingly fine grain and medium intensification factor. When both screen and paper are used together, a reduction in exposure to one third of that needed by Kryptoscreen paper alone is possible without any loss of definition.

\section{A New British Orchid}

The flora of the duneland area between Liverpool and Southport (botanically "south Lancashire", vicecounty 59 , but in all official and local nomenclature "west Lancashire") has always interested botanists well outside the local area owing to the many special forms of plants adapted to the peculiar habitat, and as a subject for plant ecology it much resembles the Flanders coast. Its list of sixteen Orchidaceæ is a special attraction and this has now been extended by the discovery and naming of a new species, Epipactis pendula (C. Thomas, J. Bot., Dec., 1941) previously regarded by local botanists as $E$. dunensis (Godfrey, "British Orchidaceæ"; Green, "Flora of Liverpool"), which in turn had for years been locally considered but an early-flowering variety of the common broad-leaved helleborine, $E$. latifolia, but with smaller, greener, less-expanded flowers. The new species was found and described in some numbers from Formby and appears to prefer the clearings by the woods, whereas $E$. dunensis proper is more typical of the open dunes.

In 1934 two Liverpool naturalists, Green and Hardy, made a floral survey of these dunes for Flora's League in the hope of creating a plant sanctuary, and this orchid was noted growing abundantly in and by the thinner pinewoods, but it was regarded as a woodland variation of $E$. dunensis. The description of the new species notes as characteristic its sturdy growth, small, opposite, arched and wavy-edged leaves, raceme of numerous pendulous flowers often tinted brown on the outside, flowers large and frequently wide open; of forty-five plants at Formby a few had more than one flowering stem. The type is in the British Museum herbarium. If all the plants previously thought to be woodland forms of $E$. dunensis are the new species it seems safe from extermination, and was possibly evolved from $E$. dunensis since this coastal area was afforested in 1889.

\section{Ultra-violet Radiation}

A SUMmary of the uses of ultra-violet radiation with special reference to lethal effects is given by J. R. Harris in the Electrician of July 10. The 'near' ultra-violet region, 3,200 A. to 4,000 A., is used for photographic and fluorescent effects, the source generally being the ultra-violet 'black' lamp, which emits a maximum radiation at $3,650 \mathrm{~A}$. The 'middle' band, $2,800 \mathrm{~A}$. to $3,200 \mathrm{~A}$., represents the therapeutical region which produces erythema; lamps emitting this radiation are the so-called sunlamps and are widely used as a tonic treatment in welfare centres. Rays in the 'far' ultra-violet region, $2,000 \mathrm{~A}$. to $2,800 \mathrm{~A}$., are lethal to bacteria; the most suitable source is the quartz mercury-vapour discharge lamp large numbers of which are used in the United States for sterilizing.

The lamps have been given the following applications. Germicidal lamps have been installed in airducts, particularly those of air-conditioning schemes. In the ward of a children's hospital, germicidal lamps have been placed in concentrating reflectors and mounted on the ceiling between the cots to prevent the free passage of bacteria by the presence of the invisible 'lethal' curtain. Lamps have been installed with successful results in a mattress factory for sterilizing the cotton, the method proving cheaper than sterilizing by placing the cotton in a room containing formaldehyde fumes. A New York hotel recently purchased a specially constructed unit of four 15-watt germicidal lamps for use in bathrooms, the whole unit being designed so that the ultraviolet rays reach the floor and walls; the lethal efficiency is stated to be 99 per cent. Small sources have been installed over the counter of a bank so as to produce an invisible 'purification wall' between cashiers and customers.

\section{A New Circuit Continuity Test}

A. F. Burns, in an article on testing of the crossbar system of telephony (Bell Lab. Rec., 20, No. 9 ; May, 1942), points out that in dialling systems a talking connexion is established through a large number of contacts, and it is desirable to test for ensuring that after the circuit is closed through to the called subscriber, there will be no open circuits in the offices through which the call passes. With the crossbar system, the sender makes a continuity test 